УДК 37.015.3

\title{
ТЕХНОЛОГИЧЕСКИЙ ПОДХОД К ФОРМИРОВАНИЮ УНИВЕРСАЛЬНЫХ УЧЕБНЫХ ДЕЙСТВИЙ У МЛАДШИХ ШКОЛЬНИКОВ
}

\section{Алгушаева Венера Рафкатовна \\ к.П.н., доцент}

ФГБОУ ВО «Башкирский государственный университет»

Аннотация: В статье рассматривается проблема формирования младших школьников как субъектов учебной деятельности. В процессе овладения структурными компонентами учебной деятельности у школьников формируются универсальные учебные действия (способность принимать учебную цель и задачу, планировать ее реализацию, контролировать и оценивать свои действия и др.), а также «мягкие навыки» (проявлять познавательную инициативу в учебном сотрудничестве, лидерские качества, креативность).

Ключевые слова: Учебная деятельность, универсальные учебные действия, «мягкие навыки».

\section{TECHNOLOGICAL APPROACH TO FORMATION OF UNIVERSAL EDUCATIONAL ACTIONS AT YOUNGER SCHOOL CHILDREN}

\begin{abstract}
The article examines the problem of the formation of primary schoolchildren as subjects of educational activity. In the process of mastering the structural components of educational activity, schoolchildren develop universal educational actions (the ability to accept an educational goal and task, plan its implementation, control and evaluate their actions, etc.), as well as "soft skills" (to show cognitive initiative in educational cooperation, leadership quality, creativity).
\end{abstract}

Key words: Learning activities, universal learning activities, "soft skills".

С 1 сентября 2022 года вступит в силу Федеральный государственный образовательный стандарт начального общего образования, утвержденный 
приказом Министерства просвещения РФ от 31 мая 2021 года №286. ФГОС устанавливает требования к достижению обучающимися на уровне ключевых понятий личностных результатов, сформированных в систему ценностных отношений обучающихся к себе, другим участникам образовательного процесса, самому образовательному процессу и его результатам (например, осознание, готовность, ориентация, восприимчивость, установка). В новом стандарте сделан акцент на развитие «мягких» навыков - метапредметных и личностных. Мягкие навыки (или по-другому гибкие, soft skills) - это дополнительные знания, умения и личные качества. Эти базовые умения и качества нужны в любой сфере деятельности. Наиболее востребованные гибкие навыки: умение работать в команде, критическое мышление, лидерство, креативность и др. [1].

Стандарт также обращает внимание педагогов на формирование yниверсальных учебных действий, которые могут быть достигнуты в процессе развития младшего школьника как субъекта учебной деятельности, таких как способность принимать и сохранять учебную цель и задачу, планировать ее реализацию, контролировать и оценивать свои действия, вносить соответствующие коррективы в их выполнение, ставить новые учебные задачи, проявлять познавательную инициативу в учебном сотрудничестве, осуществлять констатирующий и предвосхищающий контроль по результату и способу действия, актуальный контроль на уровне произвольного внимания.

В современных условиях, когда исключительно быстрыми темпами происходит обновление информации, человеку надо уметь учиться самостоятельно в гораздо большей степени, чем это требовалось когда-то. Как справедливо заметил Д.Б. Эльконин, учебная деятельность должна стать второй профессией каждого человека [7]. Учебная деятельность - это деятельность по самоизменению, ее продуктом являются те изменения, которые произошли в процессе учебной деятельности в самом субъекте.

На наш взгляд, наиболее эффективный путь формирования универсальных учебных действий и «мягких навыков» у младшего школьника - это развитие его личности как субъекта учебной деятельности. Структура учебной деятельности по мере ее формирования превращается в форму субъектной активности учащегося, выполнение компонентов учебной 
деятельности превращаются в умения, необходимые для решения любых учебных задач.

Один из подходов к выделению структурных компонентов учебной деятельности, представленных в психолого-педагогических исследованиях, рассматривает ее как систему процессов решения учебных задач [3,4]. В исследовании детализированы следующие компоненты:

- анализ задачи (определение требований задачи, установление предметной области);

- принятие учебной задачи (осознание осуществляемых способов действий);

- актуализация имеющихся у ученика знаний, необходимых для решения учебной задачи (воспроизведение как содержательных, так и операционных знаний, на основе которых ученик выбирает наиболее рациональную систему операций);

- составление плана решения задачи;

- практическое выполнение решение учебной задачи;

- контроль и оценка.

Именно эти компоненты и определяют сформированность умения решать учебные задачи.

В полноценно осуществляемой учебной деятельности контроль и оценка должны быть не только итоговыми, но и пооперационными, присутствующими на каждом этапе выполняемой деятельности (Ш.А. Амонашвили, Т.Ю.Андрущенко, Г.А. Цукерман и др.). Как правило, младшие школьники имеют представление о способах итоговой оценки, которую они связывают со школьной отметкой. Оценку же за процессом деятельности они недостаточно осознают, как не осознают и то, что оценка является неотъемлемым компонентом любой целенаправленной деятельности. [6].

Сформированное действие оценки позволяет субъекту определить наличие или отсутствие у себя общего способа решения задачи, определить меру своего продвижения в той или иной предметной области, осознать и описать собственные способы деятельности, отделить известное от неизвестного и на основе этого поставить новую учебную задачу и т.д.

Начинать работу по формированию умения оценивать учебную деятельность необходимо с первых шагов систематического обучения. 
Главными условиями, способствующими успешной выработке умения оценивать окажутся: а) вычленение оценки как специального компонента учебной деятельности, б) включение учащихся в активный оценочный процесс, четкая установка на оценку хода и результата деятельности. Поскольку действие оценки - интегральная характеристика учебной деятельности, в структуре действия оценки должны быть представлены все компоненты учебной деятельности. Именно поэтому овладение названным умением способствует осознанию школьниками процессуальной стороны учебной деятельности. Выполнение действия оценки означает установление школьниками последовательности осуществления всех компонентов учебной деятельности и осознание степени овладения ими. Каждый компонент учебной деятельности, имея свои особенности, свою специфику создает возможность формирования умения, составляющие сущность оценки. [2].

Так, в процессе овладения анализом учебной задачи и его оценки предметом оценочной деятельности будет являться правильность установления предметной области, полнота выявленных элементов предмета задачи, известных и неизвестных компонентов, правильность вычленения из задачи всех описанных отношений, которыми связаны элементы предмета задачи, выяснение характера и специфики каждого из этих отношений. Чтобы показать младшим школьникам важность умения оценивать на этапе анализа учебной задачи, учителю целесообразно использовать задачи с недостающими или лишними данными, задачи, не имеющие решения, задачи-«ловушки», задачи без вопросов и т.д., а также показывать способы осуществления оценки.

Характерной чертой учебной задачи является ориентация школьников на раскрытие общего способа действия. Действие оценки на этапе принятия учебной задачи позволяет учащемуся наметить предполагаемый способ решения задачи (прогностическая оценка), учитывать особенности уже имеющихся способов деятельности (ретроспективная оценка), позволяет определить, усвоен или неусвоен общий способ решения учебной задачи. Учащийся должен установить общий характер условия задачи и соотнести их с известными ему способами действий, т.е. мысленно включить данную задачу в круг задач, решаемых известными ему способами действий.

Решение любой задачи предполагает актуализацию имеющихся у учащихся знаний. Школьниками должны быть воспроизведены как 
содержательные, так и операционные знания. Основываясь именно на оценке собственных содержательных и операционных знаний, ученик определяет свою состоятельность или несостоятельность в решении задачи. Для того, чтобы учащиеся осознали этап актуализации знаний и значимость умения оценивать свои знания и умения, учащимся предлагаются задания, построенные на основе знаний, которыми они еще не владеют. Ситуации столкновения с трудностями в деятельности как никакие другие обращают внимание ученика на самого себя с целью пересмотра своих возможностей решения задачи.

На этапе планирования решения учебной задачи определяется конкретная система действий, отбираются необходимые операции, которые приведут к решению данной задачи. Осуществление оценки на этом этапе помогает установить связь между целью деятельности и правильно выбранной системой операций, определить последовательность и наличие всех операций, логичность, установить степень владения умением планировать свою деятельность. Учителю необходимо уделять внимание проверке и оценке правильно и неправильно составленных планов по выполнению каких либо практических задач. Учащимся предлагались для оценки деформированные планы, в которых они должны были восстановить последовательность перечней. Школьниками оценивались планы, в которых были пропущены некоторые перечни операций и они должны были, исходя из цели, дополнить планы необходимыми операциями, без осуществления которых невозможно достижения результата.

Как уже отмечалось выше, отдельными компонентами структуры решения учебной задачи являются: практическое решение задачи и контроль. Что касается контроля, то формирование контрольных действий может быть подзадачей, сопутствующей овладению младшими школьниками умением оценивать. Сама по себе оценка без осуществления контрольных действий невозможна. Однако в процессе практического выполнения задачи основную нагрузку несет на себе именно пооперационный контроль. Объектом контроля начинают выступать реально выполняемые предметные действия, проверка адекватности и последовательности предметных действий, правильности их осуществления и т.д. Коррекция процесса решения обеспечивает возможность осознанного исправления ошибок и выступает в качестве обоснования оценки. Большое внимание в обучении умению оценивать осуществление контроля 
уделялось обсуждению младшими школьниками характера допущенных ошибок, выявлению их причины. В групповом или парном обсуждении учащиеся устанавливали, была ли ошибка результатом невнимательности ученика (описка, пропуск буквы, цифры, слова и др.), или ошибка объясняется недостаточным анализом содержания задачи, неумением ученика определить цель выполнения задания, незнанием правил и способов действия, неумением составить план решения задачи и т.д. Постановка особой задачи на контроль и обеспечение учащихся средствами контроля постепенно вело к рефлексии собственных действий, осознанию поставленной учебной задачи, и последующей оценке степени ее решения.

Постепенно объектом оценочной деятельности младших школьников должна стать целостная структура учебной деятельности. Отработка приобретенного общеучебного умения проводилась на всех учебных предметах. Такая работа, проводимая по осознанию целостной структуры учебной деятельности, приводит к появлению у учащихся рефлексии, которое как отмечают Давыдов В.В., Эльконин Д.Б., является новообразованием в младшем школьном возрасте и является важнейшим условием в становлении учащегося как субъекта учебной деятельности. [5].

Таким образом, овладение целостной структурой учебной деятельности по мере ее формирования превращается в форму субъектной активности учащегося, выполнение компонентов учебной деятельности превращаются в универсальные учебные действия, необходимые для решения любых учебных задач. Познавательная активность учащегося в сотрудничестве с педагогом и одноклассниками способствует постепенному формированию «мягких навыков» у младшего школьника, таких как креативность, лидерство, умению взаимодействовать в команде.

\section{Список литературы}

1. Федеральный государственный образовательный стандарт начального общего образования: Утвержден приказом Минобрнауки РФ от 31 мая 2021 года, №286.

2. Алгушаева В.Р. Формирование у младших кольников умения оценивать учебную деятельность: дис. ... канд. пед. наук. - Санкт-Петербург: 1996. - 193 стр. 
3. Вергелес Г.И. Дидактические основы формирования учебной деятельности младших школьников: дис. ... доктора пед. наук. - Л.: 1990. 320 стр.

4. Вергелес Г.И., Конева В.С. Дидактика: учебное пособие для студентов факультетов начального образования. Изд. 2-е , исп., доп. М.: Высшая школа, 2006.

5. Давыдов В.В. Содержание и структура учебной деятельности школьников// Формирование учебной деятельности школьников./ Под ред. В.В.Давыдова и др.- М.: Педагогика, 1982. Стр. 10-22.

6. Захарова А.В., Андрущенко Т.Ю. Исследование младшего школьника в учебной деятельности.// Вопросы психологии. - 1980.- №4. - стр. 90-99.

7. Эльконин Д.Б. Психология обучения младшего школьника. М.: Знание, 1974. - 79 с. 